\title{
PRODUÇÃO CIENTÍFICA, CAPITAL SOCIAL E O DESENVOLVIMENTO REGIONAL: UM ESTUDO SOBRE O NORTE FLUMINENSE
}

\author{
Ludmila Gonçalves da Matta ${ }^{1}$ \\ ORCID: https://orcid.org/0000-0002-1548-0671 \\ Sebastião de Melo Fonseca ${ }^{2}$ \\ ORCID: https://orcid.org/0000-0003-3627-8955 \\ Recebido em: 08/04/2021 \\ Publicado em: 30/06/2021
}

\section{RESUMO}

O Norte Fluminense possui o segundo maior PIB entre as regiões do estado do Rio de Janeiro. Esse feito se deve, primordialmente, à presença de um conjunto de atividades produtivas de alto valor agregado e especializado alavancado pela indústria de Exploração e Produção de Petróleo e Gás. Na esteira dessa atividade, o setor de serviço tem se desenvolvido na região com uma ampla rede de saúde, de comércio e de educação, entre outras. O polo educacional que se formou na região possui reconhecimento nacional e é responsável por uma expressiva produção científica. Todavia, o que chama atenção na região é o fato de, apesar da presença de atividades econômicas e produtivas de alto valor agregado, de um conjunto evidente de atividades de serviço, de um polo educacional reconhecido, os indicadores sociais ficarem na esteira do estado e do País. Tendo como baliza essa constatação, levantamos o seguinte questionamento: a produção científica (capital científico) construída nas instituições de ensino tem sido convertida em capital social e contribuído para o desenvolvimento da Região Norte Fluminense? A partir desse questionamento, tivemos como objetivos mapear as instituições de ensino e pesquisa instaladas no Norte Fluminense; levantar a produção científica por meio de teses e dissertações com o "Norte Fluminense" no título; e analisar o potencial dessa produção de se converter em capital social com capacidade de gerar desenvolvimento regional. A pesquisa tem caráter exploratório e utiliza o método qualitativo, fazendo uso de dados socioeconômicos e do levantamento das dissertações e teses. Como resultado, encontramos uma vasta produção científica com capacidade de contribuir para o desenvolvimento regional, contudo, essa conversão depende da relação entre os demais atores da sociedade, da cooperação mútua, da apropriação do conhecimento gerado pelas instituições de ensino pela sociedade, o que não tem se mostrado efetivo.

PALAVRAS-CHA VE: Capital social; desenvolvimento regional; Norte Fluminense

\section{SCIENTIFIC PRODUCTION, SOCIAL CAPITAL AND REGIONAL DEVELOPMENT: A STUDY ON NORTH FLUMINENSE}

\footnotetext{
${ }^{1}$ Professora do programa de mestrado e doutorado em Planejamento Regional e Gestão da Cidade da Universidade Candido Mendes (UCAM), doutora em Sociologia Política (UENF) e membro do Observatório Socioeconômico dos Municípios Produtores de Petróleo do Estado do Rio de Janeiro (OBPETRO).

${ }^{2}$ Doutorando em Planejamento Regional e Gestão da Cidade-UCAM, mestre em Pesquisa Operacional, médico intensivista.
} 


\begin{abstract}
The northern Region of the State of Rio de Janeiro has the second highest gross domestic product (GDP, abbreviation in Portuguese) among the regions of the State of Rio de Janeiro. This is primarily attributed to the set of highadded-value and specialized productive activities leveraged by the Oil and Gas Exploration and Production industry. Following this activity, the service sector has been growing in the region with a broad network of health, commerce, and education, among others. The educational center that was established in the region has national recognition, being responsible for an expressive scientific production. But it is noteworthy that, despite the economic and productive activities of high added-value, a clear set of service activities, and a well-known educational hub, the social indicators are behind the state and the country. Having this finding as a reference, we raise the following question: has the scientific production (scientific capital) developed in educational institutions been turned into social capital and contributed to the development of the northern region of the state of Rio de Janeiro? Based on this questioning, we aimed at mapping the educational and research institutions established in the northern region of the state of Rio de Janeiro; assessing the scientific production by means of theses and dissertations containing "the northern region of Rio de Janeiro" in the title; and examining how this production has been turned into social capital with capacity to generate regional development. The research is of an exploratory scope, using the qualitative method, drawing on socioeconomic data and a survey of dissertations and theses. The result has been a large scientific production capable of contributing to regional development; this change, however, depends on the relationship between the other actors in society, on cooperation, and on the appropriation of knowledge produced by the educational institutions by society, which has not been effective.
\end{abstract}

KEYWORDS: Share capital; Regional development; Northern region of the State of Rio de Janeiro

\title{
PRODUCCIÓN CIENTÍFICA, CAPITAL SOCIAL Y DESARROLLO REGIONAL: UN ESTUDIO SOBRE NORTH FLUMINENSE
}

\section{RESUMEN}

El Norte del estado de Río de Janeiro, Brasil, es la segunda región con mayor PIB. Este éxito se debe, principalmente, a la presencia de un conjunto de actividades productivas de alto valor añadido y especializado potenciado por la industria de Exploración y Producción de Petróleo y Gas. Tras esta actividad, el sector de los servicios se ha desarrollado en la región con una amplia red de salud, comercio y educación, entre otras.El centro educativo que se formó en la región cuenta con reconocimiento nacional y es responsable de una expresiva producción científica. Sin embargo, lo que llama la atención en la región es que, a pesar de tener actividades económicas y productivas de alto valor añadido, de tener un claro conjunto de actividades de servicios, y un reconocido centro educativo, los indicadores sociales están por detrás del estado y del país.A partir de esta constatación, planteamos la siguiente pregunta: ¿la producción científica (capital científico) construida en las instituciones educativas se ha convertido en capital social y ha contribuido al desarrollo de la región Norte del estado de Río de Janeiro? A partir de este cuestionamiento, nos propusimos mapear las instituciones educativas y de investigación instaladas en el Norte del estado; recoger la producción científica a través de las tesis y disertaciones con título de "Norte Fluminense"; y analizar cómo esta producción se ha convertido en capital social con capacidad de generar desarrollo regional. La investigación es de carácter exploratorio y utiliza el método cualitativo, recurriendo a datos socioeconómicos y a la encuesta de disertaciones y tesis. 
Como resultado, encontramos una amplia producción científica con capacidad de contribuir al desarrollo regional, sin embargo, esta conversión depende de la relación entre los demás actores de la sociedad, de la cooperación mutua, de la apropiación de los conocimientos generados por las instituciones educativas por parte de la sociedad, lo cual no ha resultado efectivo.

PALABRAS CLAVE: Capital social; Desarrollo regional; Norte del estado de Río de Janeiro

\section{INTRODUÇÃO}

Desde a década de 1990 com a quebra do monopólio da Petrobras na exploração de Petróleo e Gás, a Região Norte Fluminense (NF) tem observado a chegada de grandes empresas em busca de exploração na Bacia de Campos, o que, por outro lado, a torna atrativa também para investimentos nos setores de serviço, como os da construção civil, educação, saúde e do comércio em geral, entre outros. A partir de 2007, a região também viu a atividade industrial alavancada com a instalação do Porto do Açu, um complexo portuário e industrial instalado no município de São João da Barra. Essas atividades são responsáveis pelo aumento do Produto Interno Bruto (PIB) da região evidenciado nas últimas décadas. Todavia, desde a queda do preço do barril do petróleo no cenário internacional e as mudanças no padrão de investimento para exploração do pré-sal que fica na Bacia de Santos, o município vem perdendo receita, o que impõe um desafio para a gestão pública.

Em 2018, o NF concentrava o segundo maior PIB do estado, com dois municípios São João da Barra ( $1^{\circ}$ colocado $)$ e Quissamã ( $5^{\circ}$ colocado $)$ - com os maiores PIBs per capita no estado (CEPERJ, 2020). Mas, em contraste com esse cenário, a região também era marcada pela pobreza, pela desigualdade social e pelos baixos indicadores de qualidade da educação básica e da saúde.

De acordo com a divisão regional estadual, o Norte Fluminense é composto por nove municípios, sendo eles os seguintes: Campos dos Goytacazes, Carapebus, Cardoso Moreira, Conceição de Macabu, Macaé, Quissamã, São Fidélis, São Francisco de Itabapoana e São João da Barra. Entre esses municípios, o mais populoso é Campos dos Goytacazes, com população estimada de 511.168 habitantes e, em seguida, Macaé, com 261.501 habitantes (IBGE,2020). Não por acaso, esses dois municípios concentram o setor de serviços que atende ao conjunto de municípios menores, tanto do próprio estado como de estados fronteiriços como Minas Gerais e Espírito Santo. 
O maior destaque no setor de serviços está no polo educacional que se formou na região, sendo composto por instituições de ensino e pesquisa reconhecidas nacionalmente. A primeira grande universidade a se instalar na região a partir dos anos 1990 foi a Universidade Estadual do Norte Fluminense Darcy Ribeiro (UENF) em Campos dos Goytacazes. Inaugurada em 1991, a Universidade chegou com um projeto inovador idealizado por Darcy Ribeiro, que queria implantar em Campos uma "Universidade do Terceiro Milênio". Além dela, Campos já contava com a Escola de Serviço Social da Universidade Federal Fluminense (UFF) e com a Escola Técnica Federal transformada em Instituto Federal de Ciência e Tecnologia Fluminense (IFF) em 2008.

Todavia, o que chama atenção na região é o fato de, apesar da presença de atividades econômicas e produtivas de alto valor agregado, de um conjunto evidente de atividades de serviço, de um polo educacional reconhecido, os indicadores sociais ficarem na esteira do estado e do País.

De acordo com Vasconcellos e Garcia (2014), crescimento econômico não é sinônimo de desenvolvimento. Na perspectiva de Brandão (2007), o desenvolvimento deve estar comprometido com a sustentabilidade ambiental e com a inclusão de parcelas crescentes das populações marginalizadas, aumentando a capacidade e a liberdade de decisão. O desenvolvimento deve ser pensado a partir dos diversos segmentos que compõem a sociedade compreendendo o âmbito político, legal, educacional, econômico, socioambiental, tecnológico e cultural.

Milani (2004) enfatiza que o desenvolvimento regional depende sobremaneira da articulação do capital econômico com outras formas de capital como o social e o cultural. Além disso, ele aponta que o desenvolvimento hoje passa por uma economia baseada no conhecimento, na qual, inovação, criatividade e aprendizagem passaram a ter um papel fundamental.

Tendo como baliza essa constatação, levantamos o seguinte questionamento: a produção científica construída nas instituições de ensino presentes na Região Norte Fluminense tem sido convertida em capital social e contribuído para o desenvolvimento da região? A partir desse questionamento, buscamos uma linha de pesquisa que pudesse, apesar das limitações impostas pelo objeto, estabelecer um quadro da relação entre a produção científica, o capital social e o desenvolvimento da região. Para tal, levantamos a produção científica por meio de teses e dissertações que continham, no título, "Norte Fluminense" e analisamos a relação dessa produção com as atividades econômicas/produtivas com os atores 
locais e as demais temáticas ligadas à formação do capital social e à sua capacidade de gerar desenvolvimento regional.

O estudo partiu de um levantamento bibliográfico sobre capital social e desenvolvimento regional, conceitos que fundamentam a análise. Em um segundo momento, foi feito levantamento das condições socioeconômicas do Norte Fluminense, mapeamento das instituições de ensino e pesquisa instaladas na região e levantamento das teses e dissertações na base de dados do Domínio Público e no Portal das Instituições, que serviram como eixo de análise da produção científica, a fim de demonstrar a relação desta com o desenvolvimento regional.

\section{REFERENCIAL TEÓRICO}

\subsection{Capital social e desenvolvimento regional: algumas considerações}

O termo "Capital Social” foi cunhado efetivamente no início do século XX, embora o seu significado já pairasse no imaginário humano. Hanifan (1916) foi a primeira pessoa a sistematizar o conceito, convidando o leitor a admitir a palavra "capital" apenas em seu sentido conotativo, desvinculando-o do sentido material. Desse modo, quando utiliza a expressão, não se refere a posses, dinheiro ou propriedade, mas efetivamente às características e condições que permitem um grupo social prosperar, tais como boa vontade, companheirismo, respeito mútuo e engajamento comunitário. Nesse contexto, o autor dá destaque central à escola e afirma que, antes do trabalho de construção material efetivo, a comunidade deve acumular capital social do maior número de indivíduos. Assim, quando as riquezas individuais fossem agrupadas e geridas eficazmente em uma base de boa vontade mútua, a produção efetiva e próspera incidiria sobre essa comunidade.

Contudo foi Robert Putnam quem popularizou o conceito a partir de suas obras. Para ele, o capital social é um legado forjado na experiência de diversos grupos humanos e construído historicamente. Para o autor, essa instauração de fortes laços comunitários impulsionam e estimulam a ação coletiva, gerando participação individual ativa e construção democrática. A essência conceitual "diz respeito a características da organização social, como confiança, normas e sistemas, que contribuam para aumentar a eficiência da sociedade, facilitando as ações coordenadas" (PUTNAM, 2006, p. 177). 
Putnam tem uma ótica muito peculiar acerca desse assunto. Sua teoria contempla facetas muito cotidianas dessas interações comunitárias. Seus escritos preveem a construção do capital social como algo duradouro e denso a partir de relações naturalmente erigidas em um determinado grupo social. Elas podem ter caráter bastante formal, como uma associação de pais e professores, ou ainda uma união de trabalhadores, com uma liderança bem definida e uma hierarquia intrínseca. Mas também podem adotar um modelo mais informal, como um grupo de trabalhadores que se reúne em um bar num determinado dia da semana ou frequenta a igreja junto aos domingos. Independentemente do grau de formalidade envolvido, é essa "liga" de interconexão pessoal a responsável pelo senso de compartilhamento e ajuda mútua entre as pessoas (PUTNAM, 2001).

Outra conceituação possível parte do sociólogo Pierre Bourdieu. Segundo esse autor, o capital social é um conjunto de recursos baseado em uma rede perene de interrelação e cooperação entre indivíduos, além de reconhecimento social, criando uma relação e um entendimento baseado no pertencimento a um determinado grupo. Isso não tem a ver somente com proximidade espacial, mas também cultural, material e simbólica, tornando-as indissociáveis. Há, na realidade, uma conversibilidade entre os diferentes itens nas relações diárias dos membros de cada comunidade (BOURDIEU, 1986).

Enfim, o capital social tem íntima relação com a modalidade de organização em que a sociedade se pauta. É fortemente relacionada à confiança mútua, à formação de webworking e a normas funcionais e de cooperação. Todo esse ecossistema culmina em benefício social e material para os envolvidos. Esse comportamento de solidariedade reforça os laços de confiança e expande o conceito para além do convencional. A partir daí, surgem organizações não governamentais (ONGs), cooperativas, agremiações profissionais, filantropia, comunidades religiosas e todo o tipo de coletividade que possam fortalecer conexões de benefício recíproco (PUTNAM, 2001).

Do ponto de vista teórico, sobretudo conceitual, existem pontos de convergência entre as teorias de Putnam e de Bourdieu. O primeiro revela a importância da cooperação e da coordenação otimizadas pelos laços organizacionais sociais, aliados ao sempre presente conceito de confiança. Ao passo que, para Bourdieu, tais consequências podem surgir de um determinado "amálgama grupal", ou seja, da relação de pertencimento permanente de um indivíduo em sua coletividade. Para alçar degraus sociais mais elevados, trabalhadores e produtores, sejam urbanos ou rurais, precisam de luta social permanente, sobremaneira nos locais pautados no desenvolvimento de base territorial e oligárquica. Desse modo, precisam construir alicerce social interpessoal e cooperativo desde o início de sua jornada. É 
exatamente aí que existe conflito de interesses, e o aspecto simbólico é que o autor associa a necessidade de um olhar econômico-cultural sobre essas relações (ORTEGA; MATOS, 2013). Como coloca Brandão:

O processo de desenvolvimento exige assunção da conflitualidade, a dinâmica de ação das facções das classes sociais, identificar sujeitos sociopolíticos portadores de decisão transformadora. Impõe a análise das hegemonias, dos poderes e das hierarquias, construindo mediações diversas (espaciais, sociais, políticas, monetárias, financeiras, macroeconômicas, microeconômicas, interestatais, geoeconômicas, inter-regionais, interurbanas e geopolíticas). (2010, p. 102)

$\mathrm{Na}$ visão de Brandão (2010),o desenvolvimento nacional/regional requer ativar recursos materiais e simbólicos e a mobilização de sujeitos sociais e políticos ampliando o campo de ação da coletividade tendo em vista aumentar a autodeterminação e a liberdade de decisão. Entretanto, para se extraírem benefícios duradouros e promover engajamento comunitário, não se pode simplesmente definir diretrizes impositivas a esses atores sociais. Cada realidade social é distinta e única; promover a formação de capital social envolve auxiliar os indivíduos a descobrirem por si os seus próprios caminhos a partir de incentivos, para que não haja desistência até que o objetivo seja alcançado.

Não há melhor maneira de incentivo do que ofertar ações que impactem positivamente o cotidiano de um grupamento populacional. Entre elas, a formação de centros comunitários, a pesquisa voltada para a realidade local, o incentivo à frequência escolar, a oferta de aulas noturnas (para trabalhadores diurnos) e a melhoria de estradas (para deslocamento facilitado e escoamento produtivo). Tais ações modificam realidades (HANIFAN, 1916).

A escola também se comporta como um importante tear na renderização desse entrelaçamento social, visto que desenvolve papel fundamental na consolidação de costumes e da identidade local. Pischetola (2012) destaca que a escola deveria potencializar o papel de evolução sociocultural de uma comunidade, sendo uma dessas primordiais funções a capacitação dos indivíduos para questionar déficits organizacionais em vigência no seu meio. O processo de ensino-aprendizagem seria pautado na interação escola-indivíduo-família. Isso acaba por gerar capital humano e social, embebido de troca mútua de conhecimento e impulso cooperativo.

Assim, a construção de coesões sociais no âmbito local é um imprescindível movimento para a eclosão de um desenvolvimento intrínseco, pautado na territorialidade, gerando graus variados de automação desenvolvimentista. Esse tipo de organização, com características formais e informais, é construído dinamicamente por conformações locais e 
diferentes atores que se complementam, como a sociedade civil, os empresários (micro e pequenas empresas) e a gestão pública. Basicamente, o caráter de formalidade baliza a regulação socioeconômica, enquanto as atividades informais geram laços de troca e sinergismo da atividade econômica. Essa seria a semente de um desenvolvimento endógeno.

E como salienta Brandão (2010, p. 101):

Qualquer boa noção de desenvolvimento deve ressaltar sua natureza de processo de exercitar opções alternativas frente a uma temporalidade construída e não imediata, apta a sustentar escolhas, apresentando trajetórias abertas, sujeitas a decisões estratégicas e embates em contexto incontornável de diferenciação de poder.

É por isso que, em amálgamas sociais imaturos e menos coesos, existe a necessidade de um processo catalítico com produção de um capital social artificial, criado com fluxos humanos e recursos planejados. Em última análise, isso forjaria relações de confiança mútua consequentes a um planejamento econômico idealizado, manufaturando, por fim, uma modalidade de capital social e entrelaçamento de redes (MULS, 2008).

\section{METODOLOGIA}

A pesquisa tem caráter exploratório e utiliza o método qualitativo de análise e coleta de dados. Num primeiro momento, realizamos uma revisão de literatura de conceitos que fundamentam a análise como de desenvolvimento regional, capital social e capital científico. Num segundo momento, realizamos uma análise histórica descritiva das condições objetivas do desenvolvimento socioeconômico da Região Norte Fluminense ancorada em estudos de levantamento de dados realizados pela Federação das Indústrias do Estado do Rio de Janeiro (Firjan), pelo Serviço Brasileiro de Apoio às Micro e Pequenas Empresas (Sebrae), pelo Centro Estadual de Estatística, Pesquisa e Formação de Servidores Públicos do Rio de Janeiro (CEPERJ) e pelo Instituto Brasileiro de Geografia e Estatística (IBGE). Em busca dos objetivos propostos na pesquisa, realizamos um mapeamento das instituições de ensino e pesquisa instaladas na região e um levantamento de dissertações e teses no Portal Domínio Público - uma base de dados criada pelo Ministério da Educação onde fica disponibilizado um acervo de publicação com acesso livre - e também no portal das instituições com campus na região. A busca foi realizada a partir do filtro título contendo "Norte Fluminense". Com a aplicação do filtro, foram encontradas 63 dissertações e teses nas duas bases. Após 
esse filtro, foi feita uma leitura do resumo e das palavras-chave para identificar se o conteúdo tinha relação com o desenvolvimento regional e as possíveis contribuições da pesquisa para o desenvolvimento regional.

\section{A Região Norte Fluminense: aspectos socioeconômicos e mapeamento das instituições de ensino}

Como já sinalizado, a Região Norte Fluminense é composta por nove municípios sendo que a concentração da população ocorre em dois municípios, Campos dos Goytacazes (511.168 habitantes) e Macaé (261.501 habitantes). O município com a menor população é Cardoso Moreira, com 12.821 habitantes (IBGE, 2020). A principal atividade econômica centra-se na economia do petróleo por meio da Indústria de Exploração e Produção de Petróleo e Gás da Bacia de Campos. Outro vetor importante da economia é a instalação do Porto do Açu, no município de São João da Barra, um porto-indústria que agrega na sua retroárea um importante complexo industrial.

O Porto do Açu é hoje um dos maiores complexos de infraestrutura do País: tem o terceiro maior terminal de minério de ferro do Brasil, é responsável por $25 \%$ das exportações brasileiras de petróleo, ergueu o maior parque térmico da América Latina, abriga a maior base de apoio offshore do mundo e já é o terceiro maior porto nacional em movimentação de cargas. (PORTO DO AÇU, 2020)

De acordo com estudos realizados pela FIRJAN (2018), a indústria é a principal atividade econômica da Região Norte Fluminense, com quase 50\% de participação no PIB, seguida por serviços. A região possui o segundo maior polo industrial do estado, atrás apenas da capital. Outra atividade econômica de destaque é a agropecuária, com a produção de canade-açúcar e a atividade usineira responsável pela produção de açúcar e álcool.

Em 2004, por meio de uma portaria interministerial, foi criado um Grupo de Trabalho Permanente para Arranjos Produtivos Locais. A partir dessa portaria, foi estabelecido um conjunto de ações visando o mapeamento e o desenvolvimento de arranjos produtivos locais (APLs). Campos dos Goytacazes foi beneficiado com dois APLs, o do Frutificar e o da Cerâmica Vermelha. Como indicam os estudos de Hasenclever, Fauré e Miranda (2020), o APL do Frutificar pouco se efetivou. Ele estava ancorado num programa de fruticultura irrigada e na produção industrial, com a instalação de uma fábrica de beneficiamento de frutas que encerrou suas atividades em 2010. 
Já o APL da Cerâmica Vermelha constitui-se de uma atividade tradicional na região de Campos com 114 empresas produzindo tijolos, telhas e blocos de vedação e acabamentos. De acordo com os estudos realizados por Hasenclever, Fauré e Miranda (2020), esse setor pode gerar em torno de 3.000 empregos diretos e 9.000 indiretos (HASENCLEVER; FAURÉ; MIRANDA, 2020).

A economia da região agrega $6 \%$ do total estadual de empresas, com 16 mil empresas registradas. Em razão da implantação do Porto do Açu, a região é responsável por $4 \%$ do total importado e por $11 \%$ das exportações no estado. (FIRJAN, 2018).

Mas, apesar dessa pujante economia, estudos (FIRJAN, 2018) apontam que a Região Norte Fluminense possui desafios em relação ao ambiente de negócios, principalmente na área de infraestrutura, sendo o principal deles a qualidade da banda larga, ficando na sexta pior velocidade entre as dez regiões fluminenses. Possui também desafios em relação à energia elétrica, ficando em uma posição pior do que a média estadual. Outro gargalo para o desenvolvimento está na baixa cobertura de saneamento básico.

Quando analisamos o PIB dos municípios que compõem o NF, podemos classificálos, em sua maioria, como municípios ricos. Segundo estudos de Serra (2018), essa riqueza é oriunda, principalmente, das rendas petrolíferas sendo os municípios que compõem a Bacia de Campos chamados de "petrorrentistas". A Região Norte recebe grande volume de recursos de royaltiesmais participações especiais, e os municípios de Campos dos Goytacazes, Macaé e São João da Barra são os mais beneficiados por esses recursos no estado. O papel dosroyaltiesna região também pode ser destacado pelo fato de que, em cinco municípios, a participação desse recurso na receita total supera 40\%. (SEBRAE,2015). Todavia, as questões colocadas por estudos sobre o uso das rendas petrolíferas estão no fato de essa riqueza não se transformar em benefícios para a maior parte população desses municípios. Analisando alguns indicadores socioeconômicos, podemos visualizar essa situação. 
Tabela 1 - Indicadores socioeconômicos dos municípios do Norte Fluminense

\begin{tabular}{|c|c|c|c|c|}
\hline Município & $\begin{array}{l}\text { Ranking estadual do } \\
\text { PIB per capita }\end{array}$ & $\begin{array}{l}\text { Ranking estadual do } \\
\text { IDHM } 2010\end{array}$ & $\begin{array}{c}\% \text { de } \\
\text { pobres }\end{array}$ & $\begin{array}{l}\text { Ranking estadual } \\
\text { Coeficiente de Gini }\end{array}$ \\
\hline $\begin{array}{l}\text { Campos dos } \\
\text { Goytacazes }\end{array}$ & 5 & 37 & 38 & 89 \\
\hline Carapebus & 11 & 41 & 27 & 6 \\
\hline Cardoso Moreira & 83 & 89 & 42 & 23 \\
\hline $\begin{array}{c}\text { Conceição de } \\
\text { Macabu }\end{array}$ & 87 & 47 & 30 & 31 \\
\hline Macaé & 10 & 7 & 20 & 85 \\
\hline Quissamã & 2 & 55 & 35 & 71 \\
\hline São Fidélis & 63 & 65 & 33 & 19 \\
\hline $\begin{array}{l}\text { São Francisco de } \\
\text { Itabapoana }\end{array}$ & 31 & 91 & 56 & 61 \\
\hline $\begin{array}{c}\text { São Joāo da } \\
\text { Barra }\end{array}$ & 3 & 76 & 32 & 55 \\
\hline
\end{tabular}

Fonte: Elaboração própria a partir do SEBRAE (2015)

Podemos observar a partir dos dados que, apesar de figurar entre os cinco mais ricos do estado, Campos dos Goytacazes tem $38 \%$ da população na pobreza, o que o coloca também na $89^{\mathrm{a}}$ posição entre os 91 municípios no Coeficiente de Gini, que mede a desigualdade de renda. O município de Macaé também chama a atenção em relação à desigualdade medida pelo Coeficiente Gini, ficando na $85^{\text {a }}$ posição no estado, mesmo tendo o menor percentual de pobres (apenas 20\%). Com o segundo maior PIB per capita do estado, Quissamã possui 35\% da população na pobreza. Esses indicadores chamam a atenção para a baixa conversão entre a riqueza produzida e sua distribuição na sociedade.

Quando se trata de educação, observamos mais contradições. Enquanto a região se destaca com a presença de importantes instituições de ensino superior e de pesquisa, os indicadores da educação básica não são nada positivos conforme observado no Quadro 1: 
Quadro 1 - IDEB anos iniciais 2015-2019

\begin{tabular}{|l|c|c|c|c|c|c|}
\hline \multicolumn{1}{|c|}{ Município } & IDEB 2015 & Meta 2015 & IDEB 2017 & Meta 2017 & IDEB 2019 & Meta 2019 \\
\hline $\begin{array}{l}\text { Campos dos } \\
\text { Goytacazes }\end{array}$ & 5,0 & 4,5 & 4,6 & 4,8 & 0 & 5,1 \\
\hline Carapebus & 4,9 & 4,8 & 5,0 & 5,1 & 5,1 & 5,4 \\
\hline $\begin{array}{l}\text { Cardoso } \\
\text { Moreira }\end{array}$ & 4,9 & 4,9 & 4,6 & 5,2 & 4,5 & 5,5 \\
\hline $\begin{array}{l}\text { Conceição de } \\
\text { Macabu }\end{array}$ & 4,7 & 5,1 & 0 & 5,4 & 5,7 & 5,7 \\
\hline Macaé & 5,6 & 5,7 & 5,9 & 5,9 & 6,3 & 6,2 \\
\hline Quissamã & 5 & 4,6 & 5,7 & 4,9 & 6,1 & 5,2 \\
\hline São Fidélis & 4,8 & 5,7 & 5,2 & 5,9 & 4,9 & 6,2 \\
\hline $\begin{array}{l}\text { São Francisco } \\
\text { de Itabapoana }\end{array}$ & 4,1 & 4,9 & 4,6 & 5,2 & 5,3 & 5,5 \\
\hline $\begin{array}{l}\text { São João da } \\
\text { Barra }\end{array}$ & 5,0 & 4,9 & 5,3 & 5,2 & 5,5 & 5,4 \\
\hline
\end{tabular}

Fonte: QEdu, 2021.

De uma nota que varia de 0 a 10, o IDEB dos municípios que compõem a região é considerado baixo. Enquanto a nota do Brasil foi de 5,3 e a do estado do Rio de Janeiro, 5, 2 em 2015, nenhum município do Norte Fluminense atingiu essa nota. Em 2017, a média do Brasil foi de 5,5 e a do RJ, 5,3. Apenas dois municípios (Macaé e Quissamã) atingiram ou ultrapassaram essas notas. Em 2019, a média do Brasil foi de 5,0 e a do RJ, 5,4. Apenas três municípios atingiram ou ultrapassaram a média nacional, e quatro, a média do RJ, mas o mais emblemático é observado no município de Campos dos Goytacazes, o mais bem colocado no PIB, mas que fica abaixo do Brasil e do RJ em todos os anos observados. Em 2019, obteve nota 0 , por não ter enviado os dados do exame em um número considerável de escolas.

De acordo com levantamento na base de dados E-Mec (2020), o município de Campos dos Goytacazes tem instalada a Universidade Estadual do Norte Fluminense Darcy Ribeiro (UENF) que oferece 17 cursos de graduação, 14 programas de mestrado e 12 de doutorado; a Universidade Federal Fluminense (UFF), com nove cursos de graduação e dois mestrados; a Universidade Federal Rural do Rio de Janeiro (UFFRJ), com um campus de pesquisa e extensão; o Instituto Federal de Ciência e Tecnologia Fluminense, com 12 campi no estado e um Polo de Inovação Tecnológica oferecendo cursos técnicos, 23 cursos de nível 
superior, sete programas de mestrado e um doutorado. Entre as instituições privadas, possui um campus da Universidade Candido Mendes, que oferece cursos de graduação, dois programas de mestrado e um de doutorado.

Além dessas instituições, há também, no município, instituições privadas, como a Universidade Salgado de Oliveira (UNIVERSO); a Universidade Estácio de Sá (UNESA); o Centro Universitário Fluminense (UNIFLU); e os Institutos Superiores de Ensino do Centro Educacional Nossa Senhora Auxiliadora (ISECENSA) e Instituto Superior de Educação Professor Aldo Muylaert (ISEPAM), instituição pública estadual que atua na formação de professores.

Outro município da região que agrega um conjunto de instituições é Macaé, que possui uma unidade da UENF onde fica instalado o Laboratório de Engenharia e Exploração de Petróleo, responsável pelo ciclo profissional do curso de graduação em Engenharia de Exploração e Produção de Petróleo bem como pela pós-graduação stricto sensu de mestrado e doutorado em Engenharia de Reservatório e de Exploração. Outras instituições que fazem parte desse conjunto são as seguintes: um campus do IFF, que oferece cursos técnicos, três cursos de nível superior e pós-graduação lato sensu; um campus da UFF, que oferece três cursos de nível superior; um campus da UFRJ, que oferece sete cursos de nível superior, três programas de mestrado e dois de doutorado; uma faculdade municipal, que oferece quatro cursos de graduação; e duas instituições privadas sem fins lucrativos.

O município de São João da Barra também conta com um campus do IFF, que oferece cursos técnicos na área de construção naval, petróleo e gás e eletromecânica. Assim também é o caso do município de Quissamã, que possui um campus do IFF, o qual oferece cursos técnicos na área de mecânica e informática.

\section{Resultados e discussão}

De acordo com a concepção de Putnam (2006), a cooperação e a confiança são elementos fundamentais para o desenvolvimento do capital social. Compreender o capital social a partir da produção científica no sentido estabelecido por este artigo significa observar como essa produção pode ser apropriada pelos atores locais, pelos setores produtivos e econômicos, a fim de pensar o desenvolvimento regional. Nesse ínterim, por meio da busca na base de dados, encontramos 63 teses e dissertações com o título "Norte Fluminense". Para análise, agrupamos esses trabalhos em áreas de conhecimento e buscamos estabelecer a 
relação dessas produções com as atividades econômicas e produtivas da região e a discussão sobre capital social. Agrupamos os trabalhos nas seguintes áreas: agricultura; agricultura familiar; agricultura-fruticultura; agroindústria; indústria; pecuária; meio ambiente; educação; ciências sociais aplicadas; e desenvolvimento regional.

Se somada às áreas de agricultura familiar (um trabalho) e agricultura-fruticultura (sete trabalhos), a área de agricultura (sete trabalhos) foi a que apresentou maior número de trabalhos.

Quadro 2 - Teses e dissertações com enfoque em agricultura no NF

\begin{tabular}{|c|c|c|}
\hline Título & Instituição & Área \\
\hline $\begin{array}{l}\text { Análise de desempenho de uma } \\
\text { semeadora-adubadora de semeadura } \\
\text { direta no Norte Fluminense }\end{array}$ & UENF/Produção Vegetal & Agricultura \\
\hline $\begin{array}{l}\text { Condutividade hidráulica de três } \\
\text { solos da região Norte Fluminense }\end{array}$ & UENF/Produção Vegetal & Agricultura \\
\hline $\begin{array}{l}\text { Descrição dos instares de } \\
\text { ceraeochrysa } \\
\text { Fluminense da região Norte } \\
\text { coespecíficos da América do Norte } \\
\text { e Central: a morfologia larval é um } \\
\text { caráter estável em chrysopidae... }\end{array}$ & UENF/Produção Vegetal & Agricultura \\
\hline $\begin{array}{l}\text { Morfologia comparada das larvas de } \\
\text { cinco espécies de Leucochrysa } \\
\text { (Neuroptera: Chrysopidae) da } \\
\text { região Norte Fluminense }\end{array}$ & UENF/Produção Vegetal & Agricultura \\
\hline $\begin{array}{l}\text { Produtividade do feijoeiro em } \\
\text { cultivo tradicional e tecnificado no } \\
\text { Norte Fluminense }\end{array}$ & UENF/Produção Vegetal & Agricultura \\
\hline $\begin{array}{l}\text { Relações dos NDVIs derivados das } \\
\text { bandas do ETM+, MODIS e HRV } \\
\text { simulados por meio de dados } \\
\text { 'HYPERION' para cana-de-açúcar e } \\
\text { vegetação natural no Norte } \\
\text { Fluminense }\end{array}$ & UFES/Produção Vegetal & Agricultura \\
\hline $\begin{array}{l}\text { Variabilidade espacial de atributos } \\
\text { físico-hídricos dos solos da região } \\
\text { Norte Fluminense }\end{array}$ & $\begin{array}{l}\text { UFRRJ/Agronomia (Ciências do } \\
\text { Solo) }\end{array}$ & Agricultura \\
\hline
\end{tabular}

Fonte: Elaboração própria a partir do Domínio Público e Portal das Instituições.

$\mathrm{Na}$ agricultura, o enfoque está voltado tanto para melhoria do solo quanto para produtividade. Quanto aos cultivos, o único trabalho específico foi sobre o cultivo do feijão. 
$\mathrm{Na}$ análise da área, chama a atenção a pouca incidência de trabalhos na área de agricultura familiar, com apenas um trabalho como mostra o Quadro 3.

Quadro 3 - Teses e dissertações com enfoque em agricultura familiar no NF

\begin{tabular}{|l|l|l|}
\hline Título & Instituição & Área \\
\hline $\begin{array}{l}\text { Agricultura familiar versus } \\
\text { salinização: uma abordagem } \\
\text { etnopedológica }\end{array}$ & UFF/Geografia & Agricultura familiar \\
Fluminense & & \\
\hline
\end{tabular}

Fonte: Elaboração própria a partir do Domínio Público e Portal das Instituições.

O único trabalho sobre agricultura familiar aborda a questão da salinização, um fenômeno que vem sendo observado a partir da instalação do Complexo Portuário do Açu e que tem gerado conflitos expressos na mídia local.

Dentro da agricultura, a área de fruticultura contou com uma significativa produção.

Quadro 4 - Teses e dissertações com enfoque em agricultura-fruticultura no NF

\begin{tabular}{|c|c|c|}
\hline Título & Instituição & Área \\
\hline 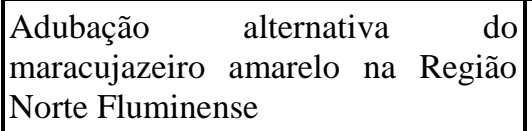 & UENF/Produção Vegetal & Agricultura-Fruticultura \\
\hline $\begin{array}{l}\text { Adubação potássica via solo e via } \\
\text { axila foliar no coqueiro anão verde } \\
\text { na Região Norte Fluminense }\end{array}$ & UENF/Produção Vegetal & Agricultura-Fruticultura \\
\hline $\begin{array}{l}\text { Desenvolvimento e produtividade } \\
\text { do abacaxizeiro 'smooth cayenne' } \\
\text { em função de adubação nitrogenada } \\
\text { e tipos de mudas no Norte } \\
\text { Fluminense }\end{array}$ & UENF/Produção Vegetal & Agricultura-Fruticultura \\
\hline $\begin{array}{l}\text { Fenologia e quebra de dormência da } \\
\text { videira Niagara Rosada cultivada na } \\
\text { Região Norte Fluminense em } \\
\text { diferentes épocas de poda }\end{array}$ & UENF/Produção Vegetal & Agricultura-Fruticultura \\
\hline $\begin{array}{l}\text { Funções de pedotransferência e } \\
\text { qualidade física de três solos do } \\
\text { norte fluminense para a cultura do } \\
\text { coqueiro anão }\end{array}$ & UENF/Produção Vegetal & Agricultura -Fruticultura \\
\hline $\begin{array}{|lrr|}\text { Recuperação de } & \text { coqueiral } & \text { Anão } \\
\text { Verde (Cocos } & \text { nucifera } & \text { L.) } \\
\text { utilizando adubos químicos } & \text { e } \\
\text { orgânicos, cobertura morta } & \text { e }\end{array}$ & UENF/Produção Vegetal & Agricultura -Fruticultura \\
\hline
\end{tabular}




\begin{tabular}{|c|c|c|}
\hline irrigação no Norte Fluminense & & \\
\hline $\begin{array}{l}\text { Nutrientes minerais em folhas e } \\
\text { bagas de genótipos de videira } \\
\text { cultivados no Norte Fluminense }\end{array}$ & $\begin{array}{l}\text { UENF/Genética e Melhoramento de } \\
\text { Plantas }\end{array}$ & Agricultura-Fruticultura \\
\hline
\end{tabular}

Fonte: Elaboração própria a partir do Domínio Público e Portal das Instituições.

Como já relatado, o município de Campos dos Goytacazes conta com o APL do Frutificar, o que pode significar uma importante relação desse APL com a produção científica voltada para o NF. Observamos, na produção científica, estudos sobre o coco, o abacaxi, o maracujá e a videira.

Ainda na área agrícola, tem-se a agroindústria, uma importante atividade econômica da região. Nessa área, encontramos três trabalhos, todos ligados à agroindústria da cana-deaçúcar.

Quadro 5 - Teses e dissertações com enfoque em agroindústria no NF

\begin{tabular}{|l|l|l|}
\hline Título & Instituição & Área \\
\hline $\begin{array}{l}\text { Competitividade da agroindústria } \\
\text { canavieira na Região Norte } \\
\text { Fluminense }\end{array}$ & UENF/Produção Vegetal & Agroindústria \\
\hline $\begin{array}{l}\text { Qualidade e identidade das cachaças } \\
\text { produzidas na Região Norte } \\
\text { Fluminense (RJ) }\end{array}$ & UENF/Produção Vegetal & Agroindústria \\
\hline $\begin{array}{l}\text { Reestruturação e revitalização do } \\
\text { setor sucroalcooleiro da Região } \\
\text { Norte Fluminense: proposta de } \\
\text { desenvolvimento de um plano de } \\
\text { negócios voltado para a produção e } \\
\text { distribuição de aguardente de ... }\end{array}$ & & Agroindústria \\
\hline
\end{tabular}

Fonte: Elaboração própria a partir do Domínio Público e Portal das Instituições.

A agroindústria, principalmente a da produção de açúcar e álcool, historicamente sempre foi a principal atividade produtiva da região, principalmente no município de Campos dos Goytacazes.

Com o declínio da cana-de-açúcar, muitas áreas que antes eram ocupadas com esse cultivo, hoje vêm sendo transformadas em pastagens. 
Quadro 6 - Teses e dissertações com enfoque em pecuária no NF

\begin{tabular}{|c|c|c|}
\hline Título & Instituição & Área \\
\hline $\begin{array}{l}\text { Aplicabilidade do uso do fungo } \\
\text { nematófago Duddingtonia flagrans } \\
\text { no controle de nematoides } \\
\text { gastrintestinais de ovinos no Norte } \\
\text { Fluminense }\end{array}$ & UENF/Produção Animal & Pecuária \\
\hline $\begin{array}{l}\text { Avaliação de cultivares de capim- } \\
\text { elefante (Pennisetum purpureum } \\
\text { Schum.) para ruminantes na Região } \\
\text { Norte Fluminense }\end{array}$ & UENF/Produção Animal & Pecuária \\
\hline $\begin{array}{l}\text { Criptosporidiose em ovinos da raça } \\
\text { Santa Inês na Região Norte } \\
\text { Fluminense-RJ: diagnóstico e } \\
\text { importância do manejo da infecção } \\
\text { natural }\end{array}$ & UENF/Produção Animal & Pecuária \\
\hline $\begin{array}{l}\text { Neosporose em vacas e fetos, } \\
\text { procedentes da Mesorregião Norte } \\
\text { Fluminense, destinadas ao abate }\end{array}$ & UENF/Ciência Animal & Pecuária \\
\hline
\end{tabular}

Fonte: Elaboração própria a partir do Domínio Público e Portal das Instituições.

$\mathrm{Na}$ área de pecuária encontramos quatro trabalhos, sendo dois específicos sobre pastagem, um sobre ovinos e um sobre bovinos.

Quadro 7 - Teses e dissertações com enfoque em indústria no NF

\begin{tabular}{|c|c|c|}
\hline Título & Instituição & Área \\
\hline $\begin{array}{l}\text { Desenvolvimento de massas } \\
\text { cerâmicas processadas por via seca } \\
\text { com matérias-primas do Norte } \\
\text { Fluminense visando aplicação em } \\
\text { revestimento poroso }\end{array}$ & $\begin{array}{l}\text { UENF/Engenharia Ciência dos } \\
\text { Materiais }\end{array}$ & Indústria cerâmica \\
\hline
\end{tabular}

Fonte: Elaboração própria a partir do Domínio Público e Portal das Instituições.

Assim como o Frutificar, a Indústria da Cerâmica Vermelha constitui um APL, e, nessa área, encontramos apenas um trabalho. Talvez isso tenha ocorrido porque nosso filtro foi o Norte Fluminense, e essa atividade está instalada apenas no município de Campos dos Goytacazes.

Outra área de destaque na produção científica refere-se ao meio ambiente, em que encontramos 12 trabalhos nessa área 
Quadro 8 - Teses e dissertações com enfoque em meio ambiente no NF

\begin{tabular}{|c|c|c|}
\hline Título & Instituição & Área \\
\hline 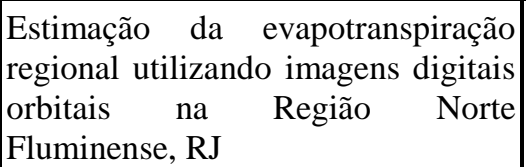 & UENF/Produção Vegetal & Meio ambiente \\
\hline \begin{tabular}{|lcrr|}
$\begin{array}{l}\text { Estudo comparativo da biologia e } \\
\text { morfologia das }\end{array}$ & \multicolumn{2}{l|}{ espécies } \\
chrysopodes & & \multicolumn{2}{c}{ (neuroptera, } \\
chrysopidae) da & Região Norte \\
Fluminense & & &
\end{tabular} & UENF/Produção Vegetal & Meio ambiente \\
\hline \begin{tabular}{llr} 
Metodologia & para a elaboração do \\
zoneamento das & áreas & sujeitas à \\
inundação & na & Baixada \\
Campista/Norte & Fluminense & - Rio \\
de Janeiro & \multicolumn{2}{l}{}
\end{tabular} & IFF/Engenharia Ambiental & Meio ambiente \\
\hline $\begin{array}{l}\text { Morfologia de gônadas de golfinhos } \\
\text { (Sotalia guianensis e Pontoporia } \\
\text { blainvillei) do litoral } \\
\text { Fluminense }\end{array}$ & UENF/Ciência Animal & Meio ambiente \\
\hline $\begin{array}{l}\text { Recuperação ambiental de áreas } \\
\text { degradadas pela extração de argila } \\
\text { na Região Norte Fluminense }\end{array}$ & IFF/Engenharia Ambiental & Meio ambiente \\
\hline $\begin{array}{l}\text { Relações de poder e } \text { gestão do } \\
\text { espaço: a criação de uma área de } \\
\text { proteção ambiental no } \\
\text { Fluminense }\end{array}$ & UFRJ/Sociologia e Antropologia & Meio ambiente \\
\hline $\begin{array}{l}\text { Sistema automatizado para } \\
\text { estimação da evapotranspiração de } \\
\text { referência e do balanço hídrico para } \\
\text { Região Norte Fluminense utilizando } \\
\text { redes neurais artificiais (RNAs) }\end{array}$ & UENF/Produção Vegetal & Meio ambiente \\
\hline $\begin{array}{l}\text { Avaliação morfoagronômica e da } \\
\text { qualidade da biomassa de acessos } \\
\text { de capim-elefante (Pennisetum } \\
\text { purpureum Schum.) para fins } \\
\text { energéticos no Norte Fluminense }\end{array}$ & UENF/Produção Vegetal & Meio ambiente \\
\hline 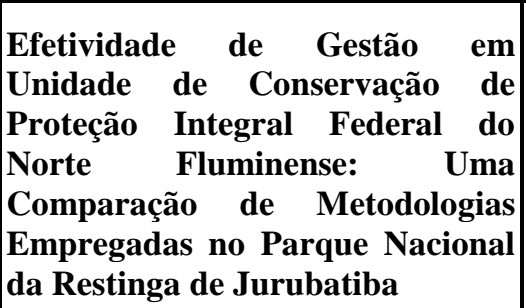 & IFF/Engenharia Ambiental & Meio ambiente \\
\hline $\begin{array}{l}\text { Avaliação dos impactos causados } \\
\text { pela implantação do Complexo }\end{array}$ & IFF/Engenharia Ambiental & Meio ambiente \\
\hline
\end{tabular}




\begin{tabular}{|c|c|c|}
\hline $\begin{array}{lccrr}\text { Portuário } & \text { do } & \text { Açu } & \text { sobre as } \\
\text { atividades } & \text { de } & \text { pesca } & \text { artesanal } \\
\text { marinha } & \text { na } & \text { Região } & \text { Norte } \\
\text { Fluminense } & & & \end{array}$ & & \\
\hline $\begin{array}{l}\text { A cadeia produtiva da silvicultura } \\
\text { como opção de desenvolvimento } \\
\text { sustentável para as Regiões Norte } \\
\text { e Noroeste Fluminense }\end{array}$ & IFF/Engenharia Ambiental & Meio ambiente \\
\hline $\begin{array}{l}\text { Zoneamento de áreas sujeitas a } \\
\text { inundações utilização de } \\
\text { geoprocessamento no estudo da } \\
\text { Baixada } \\
\text { Fluminense - Rio de Janeiro }\end{array}$ & IFF/Engenharia Ambiental & \\
\hline
\end{tabular}

Fonte: Elaboração própria a partir do Domínio Público e Portal das Instituições.

No meio ambiente, encontramos temas variados que envolvem desde recursos hídricos, controle de espécie, recuperação ambiental, energia renovável, desenvolvimento sustentável, proteção ambiental até problemas climáticos.

A área educacional, como já relatado, tem um importante papel na região e uma estreita relação com o sistema produtivo. Nessa área, encontramos seis trabalhos conforme o Quadro 9.

Quadro 9 - Teses e dissertações com enfoque em educação no NF

\begin{tabular}{|c|c|c|}
\hline Título & Instituição & Área \\
\hline $\begin{array}{l}\text { Ações políticas de melhoria da } \\
\text { qualidade do ensino: descrição e } \\
\text { análise da implementaçã da } \\
\text { política de aceleração de } \\
\text { aprendizagem na Região Norte } \\
\text { Fluminense (2004-2007) }\end{array}$ & UENF/Políticas Sociais & Educação \\
\hline $\begin{array}{l}\text { Educação e trabalho: as demandas } \\
\text { matemáticas da indústria petrolífera } \\
\text { do Norte Fluminense. }\end{array}$ & $\begin{array}{l}\text { UCAM/Planejamento Regional e } \\
\text { Gestão da Cidade }\end{array}$ & Educação \\
\hline $\begin{array}{l}\text { A valorização da língua inglesa no } \\
\text { mercado de trabalho no Complexo } \\
\text { Petrolífero do Norte Fluminense }\end{array}$ & $\begin{array}{l}\text { UCAM/Planejamento Regional e } \\
\text { Gestão da Cidade }\end{array}$ & Educação \\
\hline $\begin{array}{l}\text { Da sala de aula ao trabalho: as } \\
\text { exigências linguísticas das empresas } \\
\text { petrolíferas do Norte Fluminense }\end{array}$ & $\begin{array}{l}\text { UCAM/Planejamento Regional e } \\
\text { Gestão da Cidade }\end{array}$ & Educação \\
\hline $\begin{array}{l}\text { O Instituto Federal Fluminense no } \\
\text { desenvolvimento da Região Norte } \\
\text { do estado do Rio de Janeiro: o que } \\
\text { pensam agentes estabelecidos no }\end{array}$ & $\begin{array}{l}\text { UCAM/Planejamento Regional e } \\
\text { Gestão da Cidade }\end{array}$ & Educação \\
\hline
\end{tabular}




\begin{tabular}{|l|l|l|}
\hline território & & \\
\hline $\begin{array}{l}\text { Movimentos pendulares de } \\
\text { estudantes na Região Norte } \\
\text { Fluminense }\end{array}$ & UFF/Geografia & Educação \\
\hline
\end{tabular}

Fonte: Elaboração própria a partir do Domínio Público e Portal das Instituições.

Os trabalhos apresentam questões relacionadas à melhoria da qualidade do ensino, à relação educação-trabalho, aos movimentos pendulares e ao desenvolvimento.

Na área de Ciências Sociais Aplicadas, encontramos trabalhos com enfoque em saúde; trabalho; mercado de trabalho; gestão pública; gestão urbana; história e cultura; política e reforma agrária.

Quadro 10 - Teses e dissertações com enfoque em ciências sociais aplicadas no NF

\begin{tabular}{|c|c|c|}
\hline Título & Instituição & Área \\
\hline $\begin{array}{l}\text { Arranjos institucionais no serviço } \\
\text { de hemodinâmica das Regiões de } \\
\text { Saúde Norte e Noroeste Fluminense }\end{array}$ & $\begin{array}{l}\text { UCAM/Planejamento Regional e } \\
\text { Gestão da Cidade }\end{array}$ & Saúde \\
\hline $\begin{array}{l}\text { Território e Sindicalismo no Brasil: } \\
\text { uma análise a partir do Sindicato } \\
\text { dos Petroleiros do Norte } \\
\text { Fluminense }\end{array}$ & UFF/Geografia & Trabalho \\
\hline $\begin{array}{l}\text { Mercado de trabalho em municípios } \\
\text { do Norte Fluminense: a participação } \\
\text { de homens e mulheres }\end{array}$ & $\begin{array}{l}\text { ENCE/Estudos Populacionais e } \\
\text { Pesquisas Sociais }\end{array}$ & Mercado de trabalho \\
\hline $\begin{array}{l}\text { urso Superior de Tecnologia como } \\
\text { instrumento de inserção no mercado } \\
\text { de trabalho regional: o caso do } \\
\text { Norte Fluminense e o Cefet Campos }\end{array}$ & $\begin{array}{l}\text { UCAM/ Planejamento Regional e } \\
\text { Gestão da Cidade }\end{array}$ & Mercado de trabalho \\
\hline $\begin{array}{l}\text { Dependência orçamentária às rendas } \\
\text { petrolíferas em municípios } \\
\text { selecionados do Norte Fluminense }\end{array}$ & $\begin{array}{l}\text { UCAM/ Planejamento Regional e } \\
\text { Gestão da Cidade }\end{array}$ & Gestão pública \\
\hline $\begin{array}{l}\text { O desafio da transparência pública } \\
\text { digital nos municípios da Região } \\
\text { Norte Fluminense }\end{array}$ & UENF/Sociologia Política & Gestão pública \\
\hline $\begin{array}{l}\text { Participação cidadã e controle social } \\
\text { através do Ministério Público na } \\
\text { Região Norte-Noroeste Fluminense }\end{array}$ & UENF/Políticas Sociais & Gestão pública \\
\hline \begin{tabular}{|l|} 
As políticas culturais do Instituto \\
Estadual do Patrimônio \\
Cultural/INEPAC-RJ sob a ótica do \\
patrimônio natural na Região Norte
\end{tabular} & UENF/Políticas Sociais & Gestão pública \\
\hline
\end{tabular}




\begin{tabular}{|c|c|c|}
\hline Fluminense e seu uso turístico & & \\
\hline $\begin{array}{l}\text { O Complexo Logístico Industrial } \\
\text { Portuário do Açu e seus impactos } \\
\text { no sistema de drenagem e na } \\
\text { estruturação urbana da Região } \\
\text { Norte Fluminense }\end{array}$ & IFF/Engenharia Ambiental & Gestão urbana \\
\hline $\begin{array}{l}\text { O papel dos mediadores na } \\
\text { (re)construção da identidade étnica } \\
\text { de duas comunidades quilombolas } \\
\text { do Norte Fluminense: Barrinha e } \\
\text { Machadinha }\end{array}$ & UENF/Sociologia Política & História e cultura \\
\hline $\begin{array}{l}\text { A formação do sujeito político a } \\
\text { partir das redes pessoais: o fazer da } \\
\text { autonomia em duas comunidades } \\
\text { quilombolas do Norte Fluminense }\end{array}$ & UENF/Sociologia Política & Política \\
\hline $\begin{array}{l}\text { Participação e oposição: um estudo } \\
\text { da ação sócio-política de ONGs em } \\
\text { canais participativos municipais no } \\
\text { Norte Fluminense - 2005/2007 }\end{array}$ & UENF/Políticas Sociais & Política \\
\hline $\begin{array}{l}\text { O processo de formação dos } \\
\text { acampamentos e seus impactos no } \\
\text { processo de desenvolvimento dos } \\
\text { assentamentos de reforma agrária na } \\
\text { Região Norte Fluminense }\end{array}$ & UENF/ Políticas Sociais & Reforma agrária \\
\hline $\begin{array}{l}\text { Identificando os impactos da } \\
\text { distribuição espacial e das ações } \\
\text { coletivas na consolidação dos } \\
\text { assentamentos de reforma agrária } \\
\text { no Norte Fluminense }\end{array}$ & UENF/ Políticas Sociais & Reforma agrária \\
\hline $\begin{array}{l}\text { Potencialidades e barreiras para } \\
\text { adoção do Programa de Aquisição } \\
\text { de Alimentos (PAA) por assentados } \\
\text { da reforma agrária no Norte } \\
\text { Fluminense. }\end{array}$ & UENF/ Políticas Sociais & Reforma agrária \\
\hline
\end{tabular}

Fonte: Elaboração própria a partir do Domínio Público e Portal das Instituições.

Os trabalhos na área de ciências sociais aplicadas refletem a relação da área com as atividades econômicas e produtivas da região, o papel da indústria do petróleo e do Porto do Açu na geração de emprego e o histórico da questão agrária na região.

$\mathrm{Na}$ área de desenvolvimento regional, dentro do escopo do trabalho de pensar a região Norte Fluminense, encontramos sete trabalhos. Os trabalhos na área de desenvolvimento regional abarcam as atividades econômicas e produtivas da região, apontando para os cenários do presente conforme o Quadro 11. 
Quadro 11 - Teses e dissertações com enfoque em desenvolvimento regional no NF

\begin{tabular}{|c|c|c|}
\hline Título & Instituição & Área \\
\hline $\begin{array}{l}\text { O Complexo Portuário do Açu e } \\
\text { suas relações industriais e } \\
\text { comerciais em municípios } \\
\text { selecionados do Norte Fluminense }\end{array}$ & $\begin{array}{l}\text { UCAM/Planejamento Regional e } \\
\text { Gestão da Cidade }\end{array}$ & Desenvolvimento regional \\
\hline $\begin{array}{l}\text { Formação profissional e } \\
\text { desenvolvimento regional: uma } \\
\text { análise a partir da inserção do } \\
\text { profissional de Relações } \\
\text { Internacionais no Norte Fluminense }\end{array}$ & $\begin{array}{l}\text { UCAM/Planejamento Regional e } \\
\text { Gestão da Cidade }\end{array}$ & Desenvolvimento regional \\
\hline $\begin{array}{l}\text { Desafios ao desenvolvimento } \\
\text { regional do Norte Fluminense }\end{array}$ & $\begin{array}{l}\text { UFRJ/Políticas } \quad \text { Públicas } \\
\text { Estratégias de Desenvolvimento }\end{array}$ & Desenvolvimento regional \\
\hline $\begin{array}{l}\text { Transformações socioespaciais no } \\
\text { Norte Fluminense: da cana-de- } \\
\text { açúcar aos hidrocarbonetos }\end{array}$ & $\begin{array}{l}\text { ENCE/Estudos Populacionais } \mathrm{e} \\
\text { Pesquisas Sociais }\end{array}$ & Desenvolvimento regional \\
\hline $\begin{array}{l}\text { Transformações territoriais e } \\
\text { socioambientais do Norte } \\
\text { Fluminense: das usinas de açúcar } \\
\text { ao Complexo Logístico Industrial } \\
\text { do Porto do Açu }\end{array}$ & IFF/Engenharia Ambiental & Desenvolvimento regional \\
\hline $\begin{array}{l}\text { Potencial de produção de } \\
\text { biocombustíveis na Região Norte } \\
\text { Fluminense: avaliação da } \\
\text { integração do biodiesel com } \\
\text { usinas de etanol }\end{array}$ & IFF/Engenharia Ambiental & Desenvolvimento regional \\
\hline $\begin{array}{l}\text { Farinha pouca, meu pirão } \\
\text { primeiro: cultura, } \\
\text { desenvolvimento e o setor criativo } \\
\text { do artesanato no Norte } \\
\text { Fluminense. }\end{array}$ & UENF/Políticas Sociais & Desenvolvimento regional \\
\hline
\end{tabular}

Fonte: Elaboração própria a partir do Domínio Público e Portal das Instituições.

A partir desse levantamento, observamos que a universidade que mais possuiu pesquisa com título "Norte Fluminense" foi a UENF, com 36 dos 63 trabalhos selecionados. O programa com mais teses e dissertações foi o programa de Produção Vegetal, com 18 trabalhos, seguido pelo de Produção Animal, com cinco trabalhos. Notou-se que, em razão disso, o tema agricultura foi o mais abordado. $\mathrm{O}$ fato de a UENF possuir o maior número de teses e dissertações se deve ao fato de essa também concentrar o maior número de cursos de pós-graduação. Além dos da UENF, apareceram trabalhos da UFRJ, UFFRJ, UFES e ENCE, instituições que não possuem cursos de pós-graduação na região. Entre as universidades instaladas na região com programas de pós-graduação, apareceram na seleção a UFF, com três trabalhos ligados ao programa de mestrado em Geografia; o IFF, com nove trabalhos 
ligados ao programa de mestrado em Engenharia Ambiental; e a UCAM, com nove trabalhos ligados aos programas de mestrado e doutorado em Planejamento Regional e Gestão da Cidade.

A partir desses dados, observamos que a agenda da pesquisa está ancorada nas atividades agrícolas e voltadas para o meio rural e ambiental. Em relação às atividades produtivas da cadeia do petróleo, encontramos apenas três trabalhos com enfoque no "Norte Fluminense". Verificamos que os trabalhos sobre essa temática geralmente enfocam o município, e não a região por isso talvez tenha aparecido poucos trabalhos com a aplicação do filtro. Em relação ao Porto do Açu, obtivemos apenas dois trabalhos e constatamos também que, por estar instalado no município de São João da Barra e por ter um caráter econômico global, os olhares dos pesquisadores estão voltados para isso, e não para a região.

\section{Considerações finais}

A formação do conhecimento científico é um processo social caracterizado pela dinâmica contínua entre as dimensões social e intelectual, no qual diferentes mecanismos relacionais, cognitivos e políticos/intelectuais estão envolvidos (FREITAS, 2013). Todavia, a escolha dos temas de pesquisa muitas vezes esbarra em interesses institucionais e governamentais, visto que a maior fonte de financiamento de pesquisa são os governos por meio das agências de fomento. Quando pensamos na agenda de pesquisa inserida num contexto regional, devemos pensar como os atores locais se relacionam com essa agenda. Como coloca Freitas (2013), os processos de geração de conhecimento científico assim como a sua gestão dependem do contexto cultural. Estudos sobre a UENF, instituição que mais apareceu na pesquisa, indicam que esta possui uma cultura de estranhamento recíproco entre ela e a população local (SMIDERLE, 2008). No trabalho cujo sugestivo título é "O principado dos professores doutores na província dos coronéis", Smiderle (2008) afirma que a população local vê a UENF como "disco voador", e seus pesquisadores, como "marcianos". Já os pesquisadores percebem a sociedade local como "uma espécie de entulho pré-moderno: um lugar de coronéis e oligarquias rurais, um remanescente do escravismo no século XXI" (SMIDERLE, 2008, p. 49).

O perfil da elite local e a agenda de desenvolvimento também foram estudados por Cruz (2003), o qual aponta que um dos principais entraves para uma nova agenda de desenvolvimento para a região estaria no perfil da elite agrária que se mantém ancorada na tradição agropecuária e agroindustrial monocultural. Esse modelo legou uma mão de obra de 
baixo grau de instrução, refratária a formas de qualificação, e uma ausência de diversificação produtiva de um setor industrial dinâmico e de um empresariado voltado para a absorção de tecnologia e para a inovação (CRUZ, 2003).

Cruz (2003) conclui que o processo profundamente restrito, autoritário e excludente, de apropriação e utilização dos recursos aportados ao território do NF por grandes projetos nacionais, comandado pelas elites agropecuárias e agroindustriais, expresso num regionalismo de caráter conservador, responde pelos mecanismos de produção e reprodução das desigualdades, da pobreza e da exclusão sociais no NF, tendendo a se reproduzir nas novas elites regionais de administradores municipais que gerem as rendas petrolíferas. Como expõe Brandão (2010, p. 102), para que haja desenvolvimento, é necessário “distorcer a correlação de forças, importunar diuturnamente as estruturas e coalizões tradicionais de dominação e reprodução do poder".

Retornando à pergunta que orientou este artigo, a capacidade do capital científico de se transformar em capital social e, assim, contribuir para o desenvolvimento regional depende da relação entre os atores, da constituição de rede, de boa vontade mútua e da capacidade de esses atores criarem laços comunitários, o que, de certa maneira, não tem sido muito efetivo na Região Norte Fluminense, seja por uma agenda de pesquisa pouco articulada com as necessidades locais, seja pelo distanciamento social, como demonstrado no caso da UENF.

\section{REFERÊNCIA}

BOURDIEU, Pierre. The forms of capital. Cultural theory: An anthology. v. 1, p. 81-93, 2011, 1986.

BRANDÃO, Carlos. Território e Desenvolvimento: as múltiplas escalas entre o local e o global. Campinas: Editora da UNICAMP, 2007.

BRANDÃO, Carlos. Desenvolvimento nacional, políticas regionais e o poder de decisão segundo Celso Furtado. Cadernos do Desenvolvimento vol. 5 (7), outubro 2010. Disponível em: http://www.cadernosdodesenvolvimento.org.br/ojs-

2.4.8/index.php/cdes/article/view/270/250. Acesso em: Acesso em: 29 mar. 2021.

CEPERJ. Produto Interno Bruto dos municípios, 2020. Disponível em: http://arquivos.proderj.rj.gov.br/sefaz_ceperj_imagens/Admin/Uploads/PIB-MUICIPIOSDEZ-2020_(1).pdf. Acesso em: 29 mar. 2021.

CRUZ, José Luis Vianna. Projetos nacionais, elites locais e regionalismo: desenvolvimento e dinâmica territorial no Norte Fluminense. 331 f. Tese (Doutorado em Planejamento Urbano e 
Regional) - Instituto de Pesquisa e Planejamento Urbano e Regional, Universidade Federal do Rio de Janeiro, Rio de Janeiro, 2003.

DOMÍNIO PÚBLICO. Disponível em: http://www.dominiopublico.gov.br/pesquisa/PesquisaObraForm.jsp. Acesso em: 20 mar. 2021.

MINISTÉRIO DA EDUCAÇAO. E-Mec. Disponível em: https://emec.mec.gov.br/emec/nova. Acesso em: 20 mar. 2021.

FIRJAN. Retratos Regionais: perfil econômico regional, 2018. Disponível em: https://www.firjan.com.br/publicacoes/publicacoes-de-economia/retratos-regionais.htm.

Acesso em: 20 mar. 2021.

FREITAS, Elizabeth Jorge da Silva Monteiro de. Capital social e humano e a produção científica: um estudo sobre redes sociais de conhecimento em uma universidade pública brasileira. 246 f. Tese (Doutorado em Administração) Universidade Federal da Bahia, Salvador, 2003.

HANIFAN, L. J. The rural school community center. The Annals of the American Academy of Political and Social Science, v. 67, p. 130-138, 1916.

HASENCLEVER, Lia; FAURÉ, Yves; MIRANDA, Caroline. O desenvolvimento para além dos Arranjos Produtivos Locais (APLs): uma exploração no Norte Fluminense. Desenvolvimento em Debate. v.8, n.2, p.197-225, 2020.

IBGE. INSTITUTO BRASILEIRO DE GEOGRAFIA E ESTATÍSTICA. IBGE Cidades. Disponível em: https://www.ibge.gov.br/cidades-e-estados/rj/campos-dos-goytacazes.html. Acesso em: 28 mar 2020.

MILANI, Carlos. Teorias do capital social e desenvolvimento local: lições a partir da experiência de Pintadas (Bahia, Brasil). Organizações e Sociedade. v. 11. Edição especial, 2004, p. $\quad 95$ a $113 . \quad$ Disponível https://periodicos.ufba.br/index.php/revistaoes/article/view/12637. Acesso em: 20 mar. 2021. MULS, L. M. Desenvolvimento Local, Espaço e Território: O Conceito de Capital Social e a Importância da Formação de Redes entre Organismos e Instituições Locais. Economia, v. 9, n. 1, p. 1-21, 2008.

ORTEGA, A. C.; MATOS, V. A. Território, desenvolvimento endógeno e capital social em Putnam e Bourdieu. Política \& Sociedade, v. 12, n. 24, p. 35-60, 2013.

PISCHETOLA, Magda. Capital humano e capital social como fatores-chave de inovação na escola. EntreVer-Revista das Licenciaturas, v. 2, n. 3, p. 236-250, 2012. 
PORTO DO AÇU. Sobre o porto. Disponível em: https://portodoacu.com.br/sobre-oporto/porto-do-acu/. Acesso em: 29 mar. 2021.

PUTNAM, R. Social Capital: Measurement and Consequences. Canadian Journal of Policy Research, v. 2, n. 1, p. 41-51, 2001.

PUTNAM, R. D. Comunidade e Democracia: a experiência da Itália moderna. $5^{\text {a }}$ edição ed. Rio de Janeiro: Editora FGV, 2006.

QEdu. Disponível em: https://www.qedu.org.br/. Acesso em: 20 mar. 2021.

ROTONDANO, R. O. Entre o capital e a questão social: elementos da educação brasileira na contemporaneidade. Revista de la Facultad de Derecho, n. 48, p. 1-22, 2020.

SILVA, A. D. O.; SANTOS, C. Capital Social, Capital Humano e Educação: o ensino da sociologia e a construção da cidadania. Perspectiva Sociológica: A Revista de Professores de Sociologia, v. 0, n. 3, p. 1-15, 2015.

SEBRAE. Painel regional: Norte Fluminense / Observatório Sebrae/RJ. Rio de Janeiro: SEBRAE/RJ, 2015.

SERRA, Rodrigo Valente. Distribuir e Aplicar as Rendas do Petróleo: o debate-mãe do combativo BPRR. Petróleo, Royalties e Região - Campos dos Goytacazes/RJ - Ano XVI, $n^{\circ}$ 61 -Dezembro / 2018, p.05-06.

SMIDERLE, Carlos Gustavo Sarmet Moreira. O principado dos professores doutores na província dos coronéis. Agenda Social. Campos dos Goytacazes, v.2, n.1, jan-abr/2008, p. 48-63.

Disponível:

http://www.uenf.br/Uenf/Downloads/Agenda_Social_5273_1208282424.pdf. Acesso em: 29 mar.

2021. 